\title{
The Growth of Grain Eoundery \\ Cavities Under Applied Stress \\ and Internal Pressure
}

by

James F. Mancuso*

and

Che-Yu LI

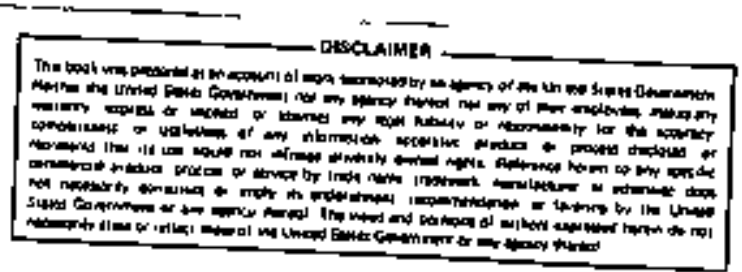

1tere is no objedion froes the patem

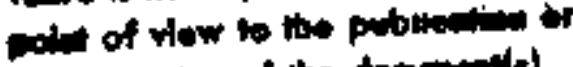

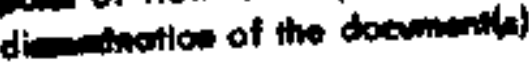
thond in thister.

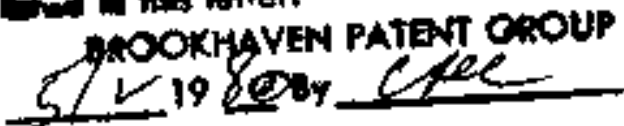

*Fornerly a graduate student at Cornell University; now at Combustion Engineering, windsor, CT.

**Cornell University, Ithace, N.Y. 


\section{DISCLAIMER}

This report was prepared as an account of work sponsored by an agency of the United States Government. Neither the United States Government nor any agency Thereot, nor any of their employees, makes any warranty, express or implied, or assumes any legal liability or responsibility for the accuracy, completeness, or usefulness of any information, apparatus, product, or process disclosed, or represents that its use would not infringe privately owned rights. Reference herein to any specific commercial product, process, or service by trade name, trademark, manufacturer, or otherwise does not necessarily constitute or imply its endorsement, recommendation, or favoring by the United States Government or any agency thereof. The views and opinions of authors expressed herein do not necessarlly state or reflect those of the United States Government or any agency thereof. 


\section{DISCLAIMER}

Portions of this document may be illegible in electronic image products. Images are produced from the best available original document. 
Abstract:

Experiments were performed to investigate the growth of grain boundary covities in nickel under internal presaure and applied stress. Inder the experimental conditions the grouth kinetics was found to be controlled by stress induced mass transfer. The growth rate was found not to be a linear function of the applied stress. The grouth rate was found to depend on grain boundary oriantation and grain boundary sliding. 


\section{Introduction}

This paper reports an experimental investigation of cavity growth at grain boundaries in nickel under internal gas pressure and applied tensile stress. Cavity growth under interagl gas pregture is an important damage mechanism during hydrogen attack at elevated temperatures [1], while cavity growth under spplied tensile stress is an fmportant damage mechanism during creep at lower stresges and can lead to intergranular failure [2].

Th1s work addresses cavity growth due to stress 1nduced diffusion. The kinetics of this phenomenon have been considered by several investigators, who have show that the driving force for growth is the normat stress at the grain boundary. They concluded that the radial growth rate should be linearly proportional to the epplied stress $[3,4,5]$. However, this dependence has not been observed experimentally even at low stress where cavity growth due to grain boundary shearing is not important [6]. A mejor objective of this experinent is to investigste the reported non-linear stress dependence under conditions where diffusion controlled cavity growth is iaportant. It is expected that the resurts of this work will be applicable to the development of hydrogen attack damage models as well as to ereep-to-rupture analyses.

In order to investigate cavity growth under applied stress without the influence of cavity nucleation, we have prepared nickel specimens with preexisting cavities for the growth studies. The initial cavities were produced by exposing the specimens to high pressure (3.5 - 14.5 MPa) hydrogen gas at elerated temperatures $\left(300-500^{\circ} \mathrm{C}\right)$. Goorth rate was determined for a number of combinations of applied stress and temperature. Special attention was given to deteraining how the growth rate varied with the engle between the grain boundary surface and the applied stresa axis. 


$$
-2-
$$

\section{Experiment}

The detailed description of the experimental procedure is given in Reference [ 7$]$. Nickel 270 specimens were fabricated from 2.4 cm diameter bar stock obtained from Internationel Nickel Inc. The bar was swaged to a diameter of $0.36 \mathrm{~cm}$ and recrystallized to echieve the desired grain size. The final fpecimen length was approximately $6 \mathrm{~cm}$ for growth studies without applied stress and $3.1 \mathrm{~cm}$ for growth studies under an applied stress.

Cavities were produced by methane reaction resulting from exposing the nickel specimens conteining dissolved carbon to high pressure hydrogen gas. at $500^{\circ} \mathrm{C}[1]$. Two types of exposure conditions were used. One produced grain boundary cavities that contafned excess gas presgure which provided a driving force for continued cavity growth upon subsequent annealiag in the absence of a hydrogen entiromment. The other set of exposure conditions ylelded cavities with an equilibriun gas pressure. These cavities grev only under an applied stress in the absence of a hydrogen eavironment.

Growth studieg without applied stress were performed by vecuum annesls at 500,550 and $600^{\circ} \mathrm{C}$ with the internal-methene pressure of the cavity as the driving force for growth. For each experimental sequence at a given temperature a single 6 cin rod was used. A section of the rod was removed at different time intervals to determine cavity sizes as a function of time. The cavity cross-sectional areas were determined from intergranuzar tracture surfaces by scanning electron microscopy (SEM). The detailed method of preparing the fracture surfaces ig described in Reference [7]. A typical SEM photomicrograph of cavities on a grain boundary is stow in Figure 1. An example of the cavity size distributions obtained is shom in the histograms in Figure 2. More than 100 carities were counted for the determination of an average cayity size. 
The study of cavity growth under applied tensile stress employed specimens that had a 3.1 cm gauge length and contained cavities with an equilibrium methane gas pressure. The experiments vere performed under constant load at 500 and $550^{\circ} \mathrm{C}$. Strain of the specimen was nonitored during the experiments. The amount of cavity growth due to the applied stress was determined by comparison of cavity cross-sectional sress in the stressed and unstressed portions of the specimens. Stereographis SBN of the frecture surface was uged to determine cevity size as a function of the exain boundary orientation as determined by a stereographic technique $[\tau, 8]$.

\section{Results and Discussion}

\section{Carity Growth Under Internal Pressure}

Experimental data obtained from the vacuum annealing experiments are show in Figure 3 which contalns a plot of the meen cross sectional area of the cavities against a reduced (annealing) time, Dt, where $D$ is the grain boundary diffusion constant [ 9 ] and $t$ is the time at the annealing temperature. The time dependence of cavity size suggest diffusion controlled growth. In the same plot, tbe calculated growth curves based on the diffusion controlled growth model are shown, whereby the rate of growth is expressed by $[4,5]$ :

$$
\frac{d r}{d t}=\frac{w D}{k T}\left(\frac{\Omega}{t^{2}}\right) \frac{\left(\sigma_{n}-\left[\frac{2 Y}{r}-P\right]\left[1-\left(\frac{2 r}{a}\right)^{2}\right]\right\}\left[\left(\frac{2 r}{a}\right)^{2}-1\right]}{2\left[\frac{3}{4}+\frac{1}{4}\left(\frac{2 r}{a}\right)^{4}+\ln \left(\frac{2 r}{a}\right)\left\{\frac{2 r}{a}\right)^{2}\right\}}
$$

where

$$
\begin{aligned}
& D \text { is the grain boundary diffusion coefficient } \\
& y \text { is the wdath of the grain boundary } \\
& r \text { is the radius of the cavity } \\
& \sigma_{n} \text { is the nornal stress on the grain boundary } \\
& P \text { is the internal gas pressure in the cavity } \\
& Y \text { is the surface tension }
\end{aligned}
$$


$\Omega$ is the atonic volume

a is the center-to-center cavity spacing

$k$ is Boltzman's constant

$\mathrm{i}$ is the absolute temperature

The internal pressure has been eatimated by using the ideal ges law, the asyutotic value of the cavity size for long annealing times and the equilibrium gas pressure relationship, $P=\frac{2 Y}{r}$. The relues of $D$ and $Y$ were obtained fron the literature $[9,10]$. The solid lines represent numerical integrations of the growth rate over time. The comparison between the calculated curves and the data suggests that stress induced diffusion is the cavity growth mechan1sm. Nore 1mportant to the purpose of the present work this comparison supports the validity of using the values of $D$ and $\gamma$ found in the literature for the calculation of cavity growth under applied stress.

\section{Cavity Growth Under Applied Stress}

2a. Average Cavity Growth Rate

Cavity growth rates averagod over all grain boundary orientations are plotted versus the spplied tensfle stress in Figures 4 and 5 for the two test temperatures. These dsta exhibit a non-linear stress dependence. The conditsons of the experimenta were auch that grain boundary shear was not expected to be an important mechanism for cavity growth [7]. The solid lines in the same figires are growth predictions besed on Equation 1 , the values of $D$ and $\gamma$ established in the previous section and the assumption that $\sigma_{n}=T / 2$ where $T$ is the applied tensile stress and $T / 2$ is the everage normal stress on the grain boundaries, The dats in Figs. 4 and 5 suggest that tho agreement between the model predictions and the experimenal resurts improves as the applied stress incresses. These data suggest also the possibility that the linear stress dependence expected from the growth model (Equation 1) will be exhibited for stresses higher than those employed In the present work, provided other growth mechanisms do not become important. 
In the next section we will attempt to show how the non-linear stress dependence observed in this work is resated to grain boundary sliding as suggested by the analysis of the effect of grain boundary orientation on the cavity growth rate.

\section{2b. Effects of Grain Boundary Orientation}

It is well established that grain boundary sliding is an important deformation mechanism at low strain rates for ereep at temperatures near one-half the melting point. Under the sams conditions one usually observes intergranular feilure with reduced ductility in a creep-to-rupture test. The existence of grain boundary sliding has been demonstrated in speclnens used to obtain date for Flgures 4 and 5. A detalled discussion of the evidence for grein boundary sliding is given in Reference 7 . The most direct indication of the exigtence of grain boundary sliding in these specimens was the emergence of grain boundary steps on the surface of the specinen after creep.

Grain boundary sliding is believed to produce stress concentrations' at grain corners. A schewatic representation of the expected stress concentration (taken from Reference II) is show in Figure 6. Qualitatively the stress concentrations that are produced by sliding will lesd to redistribution of the stregses at the grain boundaries such that the grain boundary normal stresses will be reduced. At higher stresses where grein boundary sliding is not important the normal stress at the grain boundary will essentially be equal to $T \cos ^{2} \theta$ where $\theta$ is the angle between the grain boundary normal and the tensile gtresg axis and $T$ is the applied uniaxial stress. The above relation suggests the maximum cavity Browth to occur at grain boundarfes lying perpendicular to the applied stress axis $(\theta=0)$, while no growth should occur at boundaries parallel to the stress axis $\left(\theta=90^{\circ}\right)$. 
Using the $\cos ^{2} \theta$ depenence for $\sigma_{n}$ and Equation 1 with the values of $D$ and $Y$ discussed previously we can celculate the cavity growth rate as a function of the grain boundary orientation $(\theta)$ at a given temperature and applied stress. The results of this type of calculation are shown as solid lines in Figures 7 and 8, in plots of cavity growth rate versus grain boundary angle. Cavity growth date are also shown in the same figures.

The data from Figure 7 were obtained from the game specimen used to measure the average cavity growth rate st the highest stress in Figure 5 . We have pointed out in a previous discussion that the agreement between the measured growth rate and the model predictions improves at this stress level. This observation is consistent with the data in Figure 7 where the measured orientetion dependence of the cerity growth rate approximates that predicted by a $\cos ^{2} \theta$ dependence of the normal stress. This agreement supports diffusion controlled cavity growth. This type of ortentation dependence suggests that, at the higher stress levels, grain boundary sliding is not important and that significant redistribution of the stress at the grain boundaries will not occur.

In contrast the data in Figures $8 \mathrm{a}$ and $8 \mathrm{~b}$ were obtained at lower stresses show in Figures 4 and 5 whert the average cavity growth rate differs significantly from the model predictions. The observed deviations in the direction of lower growth rates compered to the calculated values in Figure 4 and 5 are believed to be a consequence of the measured orientation dependence in Figures $8 \mathrm{a}$ and $8 \mathrm{~b}$. The neasured eavity growth rate at lower stresses in these figures shows essentially none of the orientation dependence predicted by using the geometrickl factor $\cos ^{2} \theta$. These data suggest that grein boundary sliding is more important at lower stresses Euch that stress redistribution will occur leading to the observed results. We may conclude that the non-linear stress dependence of the cavity growth rate observed here and in reported work [12] is a consequence of 
stress redistribution at grain corners due to graln boundary sIiding.

3a. Discussion

The results of this work confirm the previoug observations that the average cavity growth rate is not a IInear function of the applied stress in the stress range where cavity growth is controlled by stress induced mass transport. These results suggest the need to account for the effect of grain boundary sliding on the stress redistribution at the grain boundary so that we can have better cavity growth calculations in order to estinate properly the rate of creep damage accuriation. At present the required model for this effect does not exist. The type of data obtained in this work on the orientation dependence of grain boundary cavity growth can be used to experimentally determine the extent of stress redistribution which can be used as a useful basis for future model development.

\section{Acknowledgements}

The authors wish to acknowledge the support of the Department of Energy, They also wish to thank R. Cheney of GTE Sylvanta for performtng swaging operations as pert of the specimen fabrication process.

\section{References}

1. P.G. Shewmon, Met. Trans., 1976, 7A, p. 279.

2. F. Gerafalo, Fundamentals of Creep and Creep Ruptire in Metals, p. 2lo, Mackillan Co., N.Y., 1965.

3. D. Hull and D.E. Rimmer, Phil. Mag., 1959, 4, p. 673.

4. J.F. Mancuso, F.H. Hueng and Che-Yu Li, Fundamental Aspects of Rad. Dam. in Metals, 2, M.T. Robinson and F.W. Youngs Bd., Oct. 1975, P. 1279.

5. R. Raj and M.F. Ashby, Acta Met., 1975,23, p. 653.

6. J.K. Greenwood, J. Iron and Steel Inst., 1954, 176, p. 268.

7. J.F. Mancuso, Ph.D. Thesis, Cornell University, 1977.

8. G.S. Lane, J. Fhy. E., 1969, 2, p. 545. 
9. A.R. Wazan, J. Appl. Phys., 1965, 36, p. 3596.

10. J.M. Blakely, Introduction to the Properties of Crystal Surfaces, p. 64 , p. 64, Pergamon Press, 1973.

11. E.\$. Hart, Acta Met., 1967, 15, p. 1545 .

12. B.J. Cane, and J.N. Greentrood, Met. Sei., 1975, 9, D. 55. 


\section{Pigure Captions}

Figure 1: SEM photomicrograph of typical grain boundary cavities produced by hydrogen attack of nickel specimens.

Figure 2: Examples of cavity size (cross-sectional area) distributions observea. The distributions shown above were obtained in a cavity annealing experiment at $500^{\circ} \mathrm{C}$. They show thet carities created with greater than equilibritu internal gas pressure will grow upon subsequent anneals in the absenge of a hydrogen atmosphere. ( $T$ = annealing time and $A=$ mean cavity eross-gection).

Figure 3: Plot of cavity cross-sections versus the reduced annealing time, Dt. Data that were obtained after 500,550 and $600^{\circ} \mathrm{C}$ amealing are shown as syabols. The solid lines represent growth predictions based on a diffusional growth model (Equation 1) and the estimated initial cavity gas pressures.

Pigure 4: Plot of average cavity growth rates (cross-sectional area/time) vs. the epplied tensile stress for creep tests performed at $500^{\circ} \mathrm{C}$. Data are shown as symbols while the solid line represents the results of calculations based on Equation 1 and the average normal stress on the grain boundaries for a given applied stress.

Figure 5: Plot of average cavity growth rates (cross-sectional area/time) vs the applied tensile stress for creep tests performed at $550^{\circ} \mathrm{C}$. Data are shom as symbols whlle the solid lines represent the results of ealculations based on Equation 1 and the average normal stress on the grain boundaries for a given applied stress.

Figure 6: Two dimenstonal idealization of the stress concentrations produced by grain boundary sliding in a polycrystalline material [11]. 
F1gure 7: Plot of the stress induced cavity growth rate versus $\theta$ (the angle between the grain boundary normal and the applied stress axis) for ereep experiments performed at $550^{\circ} \mathrm{C}$. These data (circles), obtained at the highegt stress shown in Fig. 5, show good agreement with the calculated growth rates based on Equation 1 and the relationship $\sigma_{\mathrm{n}}=\mathrm{T} \cos ^{2} \theta$.

Figure 8: $(a, b)$; Plots of the stresa Induced cavity growth rate versus $\theta$ for low strain rates. Predictions based on Equation 1 and the reletionship, $\sigma_{n}=T \cos ^{2} \theta$, are shown as solid lines in the figures. These data show poor agreement with the model predictions. 


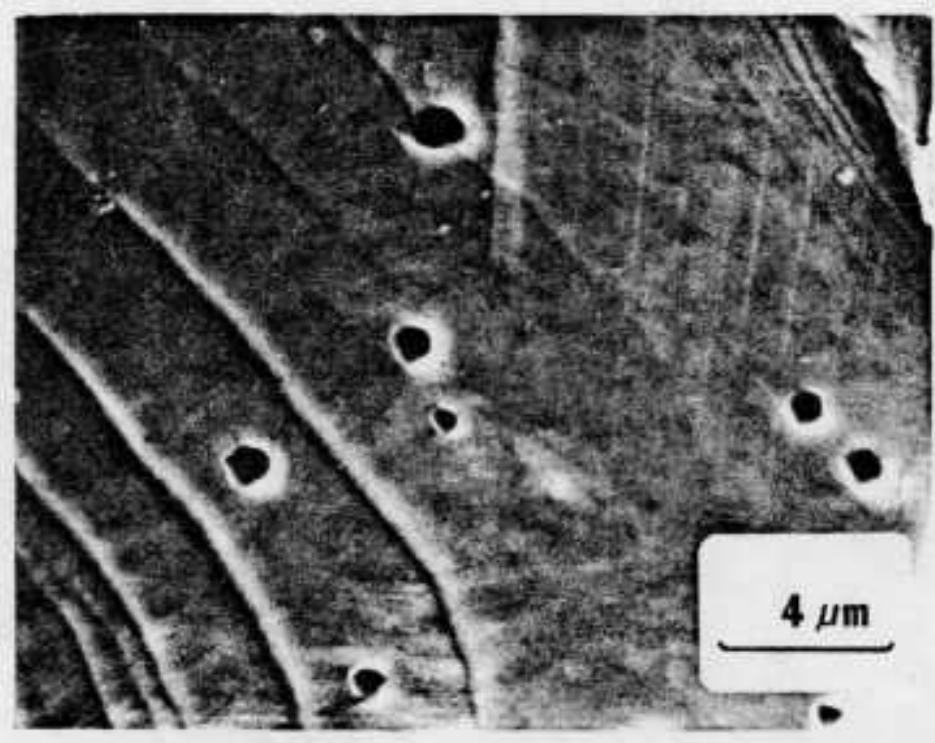

Fig. I 


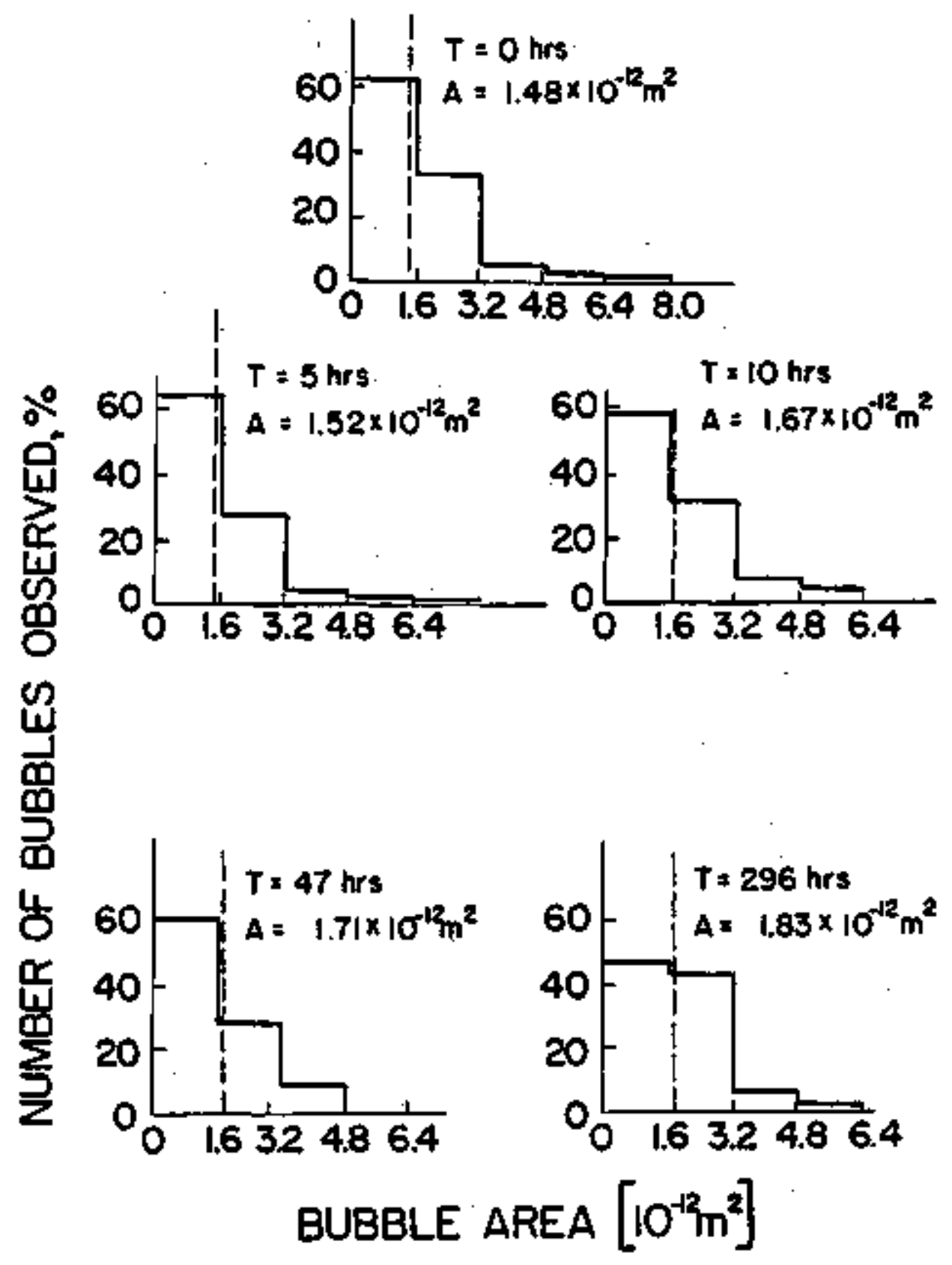

Fig. 2 


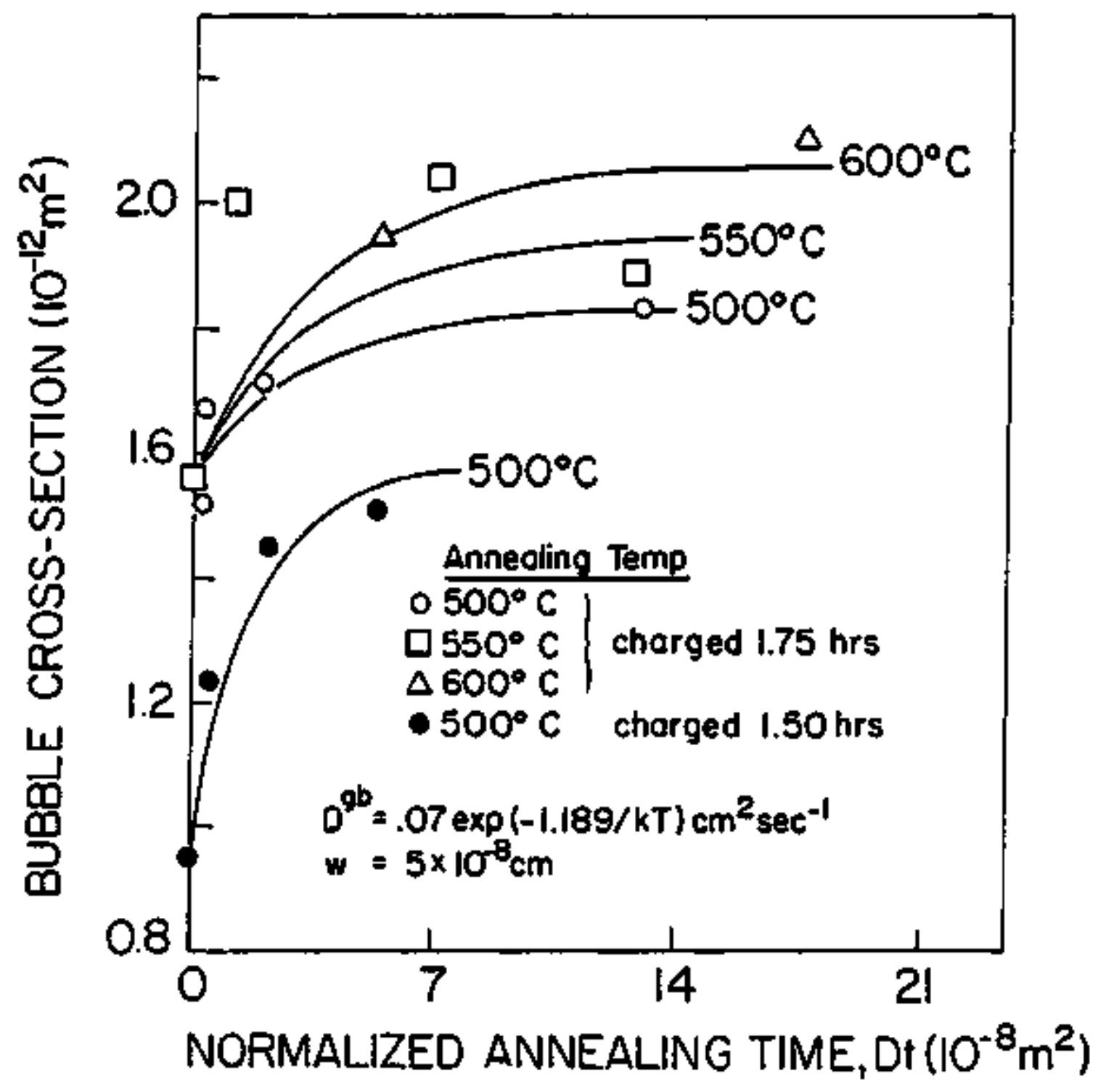

Fig. 3 


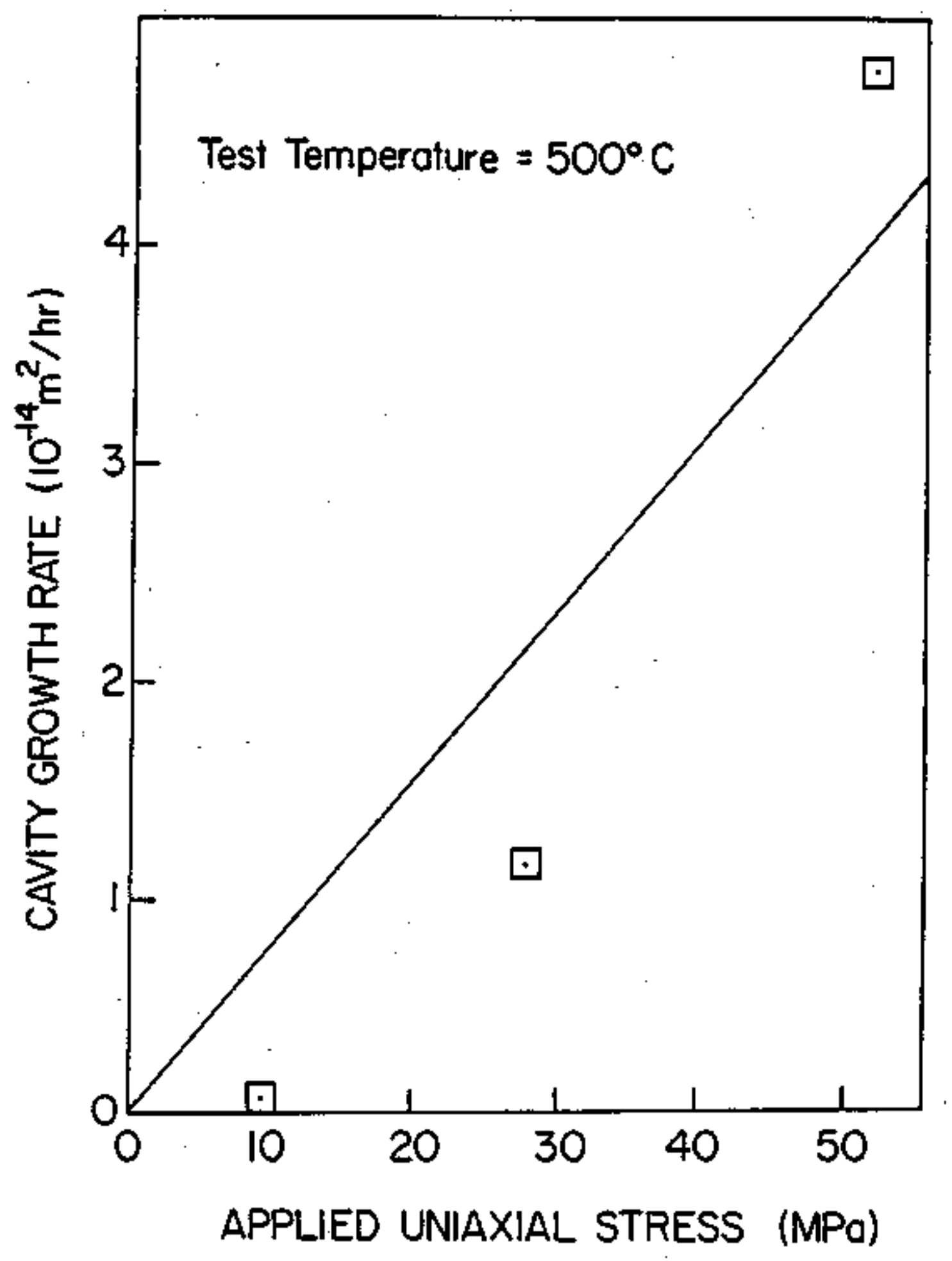

Fig. 4 


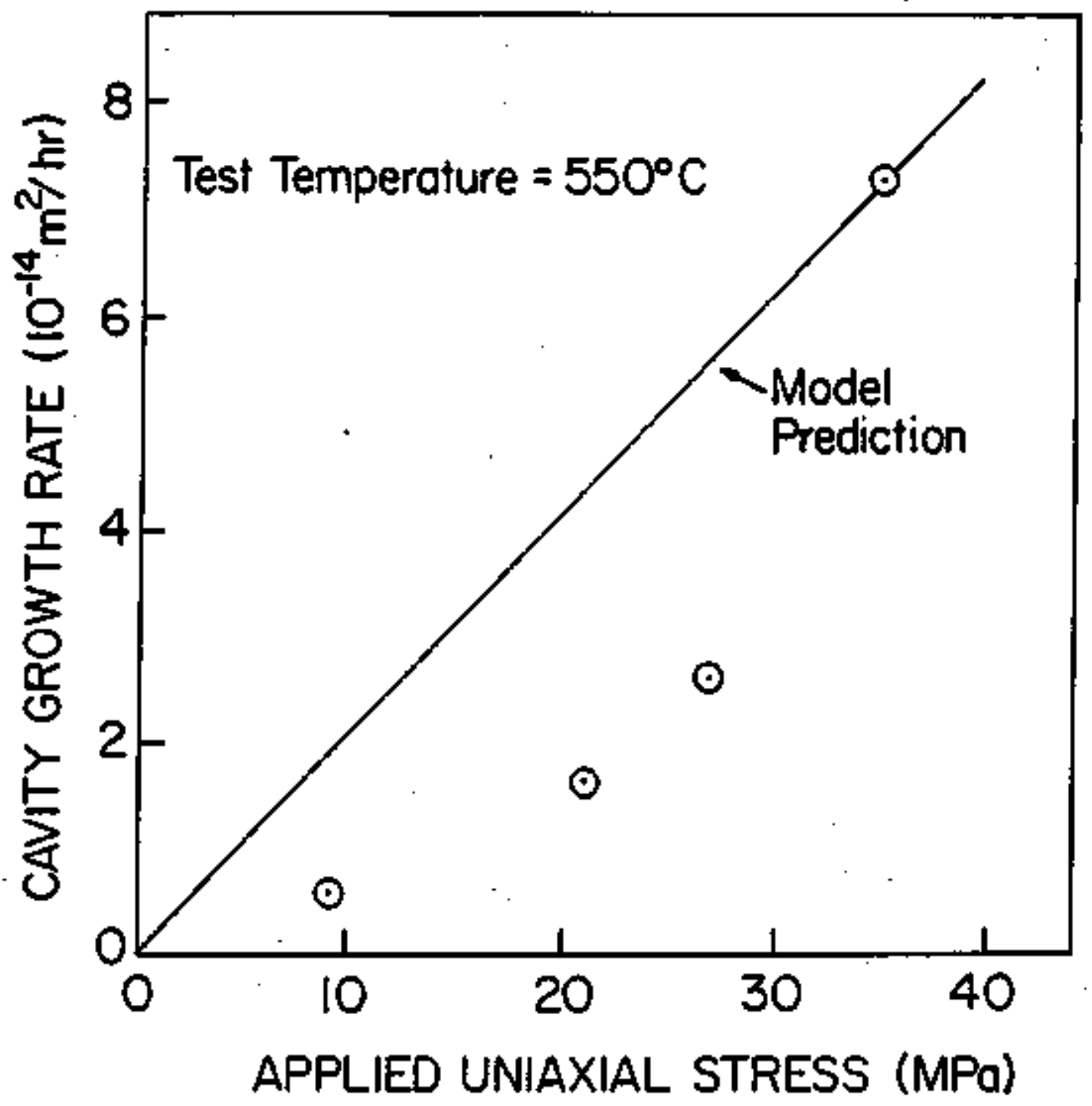

Fig. 5 


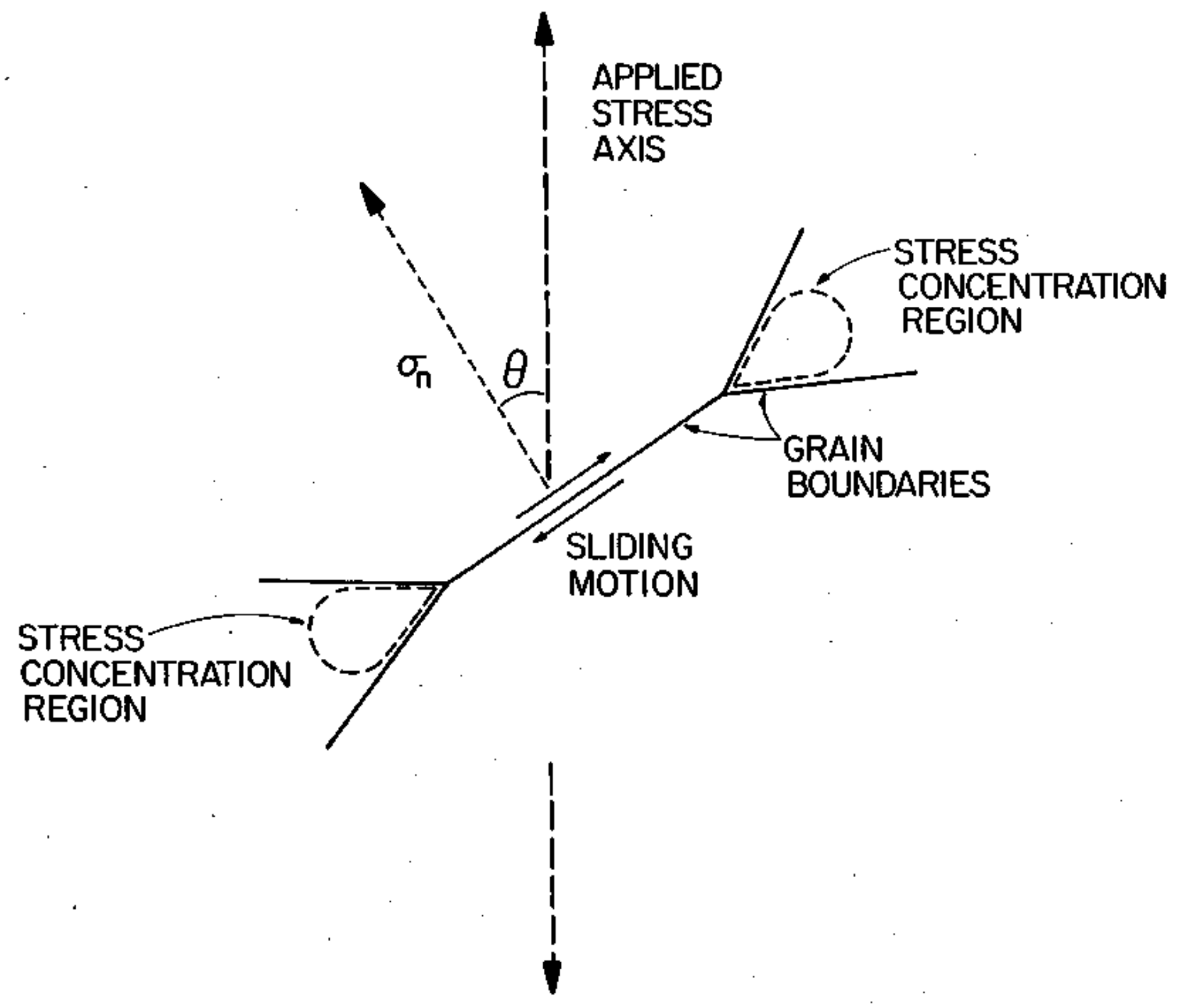

Fig. 6 


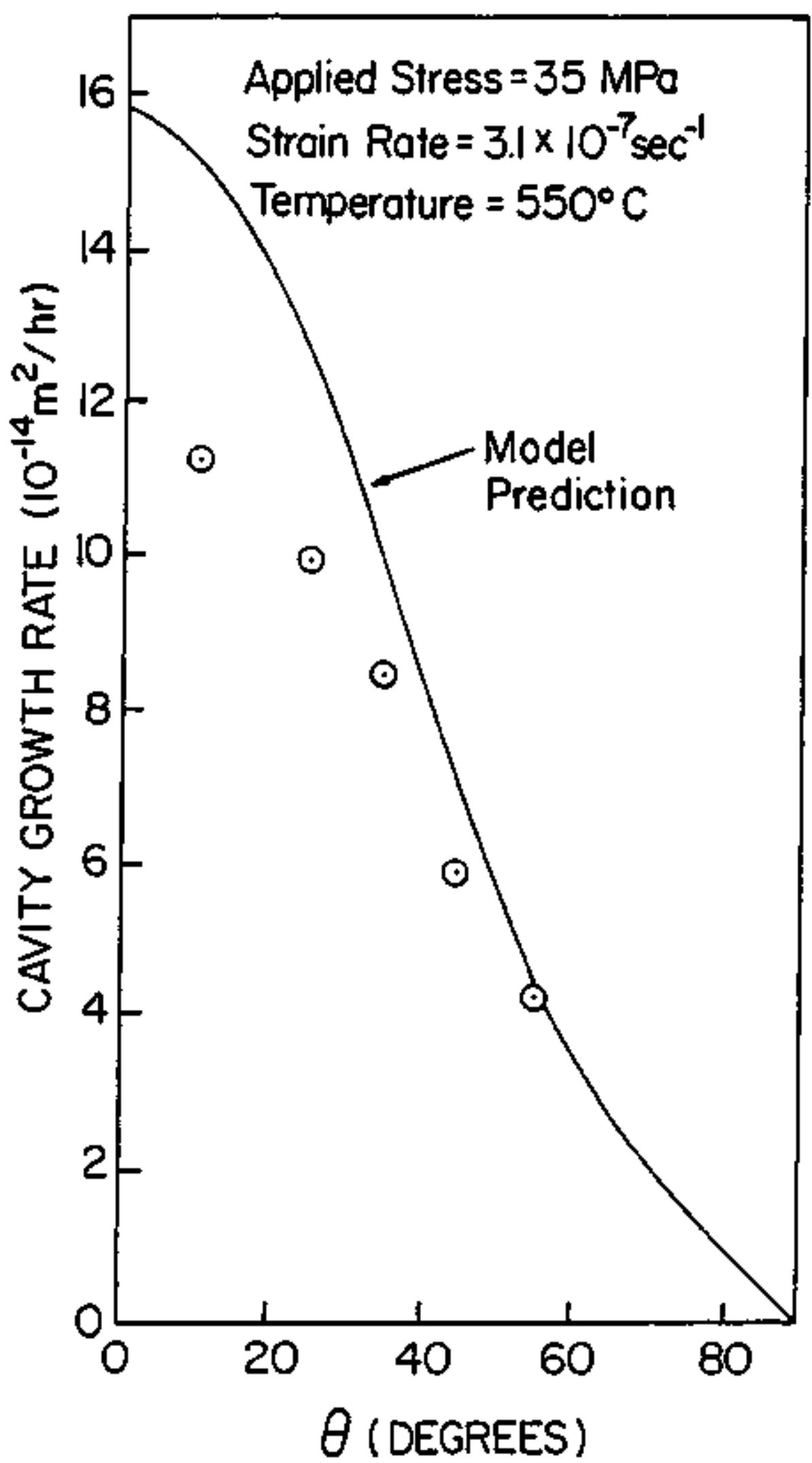

Fig. 7 


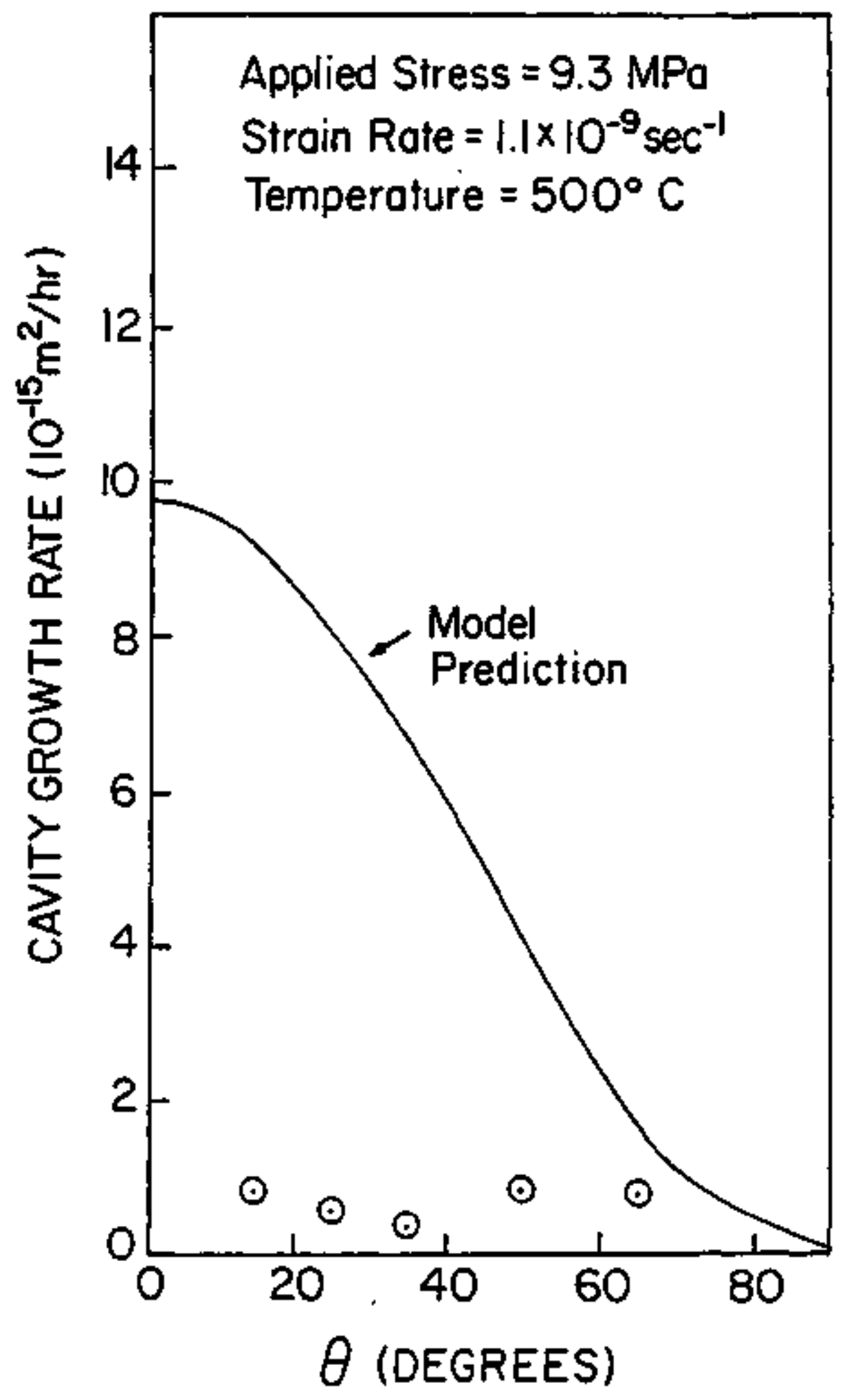

Fig. 8a 


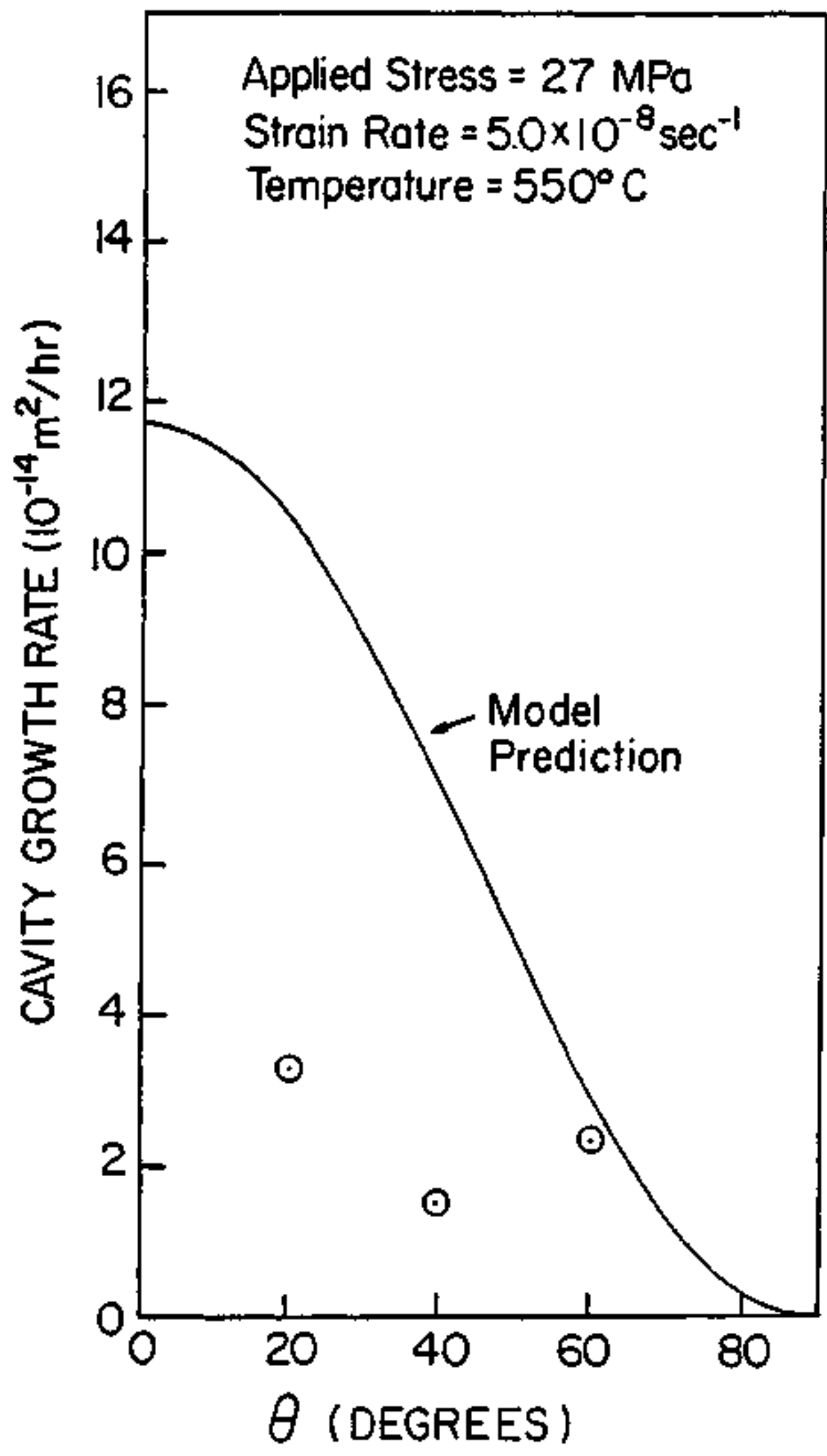

Fig. 8b 